\title{
Eco-environmental quality evaluation of Huaibei Plain
}

\author{
MIN XU ${ }^{1}$, YONGHUA ZHU ${ }^{1}$, HAISHEN LÜ ${ }^{1}$, YUAN LI ${ }^{1}$, XIAOZHEN ZHOU $^{1} \&$ \\ YANING CHEN ${ }^{2}$ \\ 1 College of Hydrology and Water Resources, Hohai University, Nanjing, Jiangsu Province, 210098, China \\ minxu0917@163.com \\ 2 State Key Laboratory of Desert and Oasis Ecology, Xinjiang Institute of Ecology and Geography, Chinese Academy of \\ Sciences, 830011, China
}

\begin{abstract}
In recent years, the destruction of the ecological environment in Huaibei Plain has limited the development of the economy. Doing research on eco-environment quality evaluation methods may be helpful to the recovery of the eco-environment in Huaibei Plain and the construction of ecological civilization. A new assessment system was introduced in this paper on the basis of a traditional ecoenvironmental evaluation method; the NPP index was used to replace biological abundance index and vegetation coverage index. This new method was used to evaluate the eco-environment quality of Huaibei Plain. Results indicate that: (a) the eco-environment of Huaibei Plain has been getting worse since 1990, but has improved since 2000; (b) the water-network density index is the key factor which affects the ecoenvironment of Huaibei Plain; (c) If human activities, pollution control, land degradation and urban area development are not taken into consideration, the eco-environment of Huaibei Plain in dry years will be serious.
\end{abstract}

Key words Huaibei Plain; eco-environmental quality evaluation; eco-environmental quality index; NPP

\section{INTRODUCTION}

Human survival is based on the eco-environment. In recent years, there have been serious environmental problems worldwide, such as environment pollution, deforestation and the scarcity of water resources. The damage of the eco-environment has become more and more serious since 1978 when China's reform and opening-up policies were launched. Eco-environmental problems have become increasingly outstanding in China (Wang et al., 1997), and there is an urgent need to construct water ecological civilization (Liu, 2013).

Eco-environmental quality, which is based on ecological theory can be used to estimate the quality of an ecosystem. The result indicates whether the ecosystem is sustainable to human survival and economic development during a period of time in a certain field. The results will show the status of the ecological environment and transition according to the requirement of people. Eco-environmental quality evaluation chooses typical and operable indexes to estimate the quality of the ecosystem environment according to specific purposes. A better eco-environment quality means less possibility of eco-system retrogression. We are able to judge whether the retrogression happens in the study area from this point of view. A further investigation should be done to determine the main factor if deterioration exists. Various methods have been employed to reveal the regional eco-environmental situation. There are some methods always used in research, such as the index evaluation method (Liu et al., 2008), the analytic hierarchy process method (AHP) (Yu et al., 2002), fuzzy comprehensive evaluation method (Li et al., 2003), artificial neural network evaluation method (Li et al., 1995), and eco-environmental quality evaluation method (Zhu et al., 2012).

In this paper, the net primary productivity (NPP) has been introduced to replace the biological abundance index and vegetation coverage index. A new evaluation index system is established to evaluate eco-environmental quality. This paper utilizes this improved eco-environmental evaluation method to study the influence of LUCC on Huaibei Plain on the ecosystem. We are able to have a better understanding of the eco-environmental degree of Huaibei Plain. The results indicate that this new method is capable of reflecting the environmental quality effectively which will provide a sustainable development strategy for government. 


\section{MATERIAL AND METHODS}

\section{Study area}

Huaibei Plain is located in the north of Anhui Province at $114^{\circ} 55^{\prime}-118^{\circ} 10^{\prime} \mathrm{E}, 32^{\circ} 25^{\prime}-34^{\circ} 35^{\prime} \mathrm{N}$, with a total area of $37437 \mathrm{~km}^{2}$. Climate of the plain is characterized as subtropical continental monsoon. It is seriously affected by natural disasters, especially flood and drought. Because Huaibei Plain is located in the middle reach of the Huaihe River, its ecological status is very important for maintaining an ecological balance of the water system, and promoting healthy development of the society and economy in the middle and lower reaches of the Huaihe River.

However, in the recent 20 years, with the rapid development of socio-economics, some ecoenvironmental problems have appeared such as the degradation of biomass, water pollution caused by industry and land degradation. Therefore, the eco-environmental quality of the whole area has been damaged and even become one of the major factors restricting the sustainable development of the plain.

\section{Data}

The amount of solid waste discharge, $\mathrm{COD}$ emissions and $\mathrm{SO}_{2}$ emissions are derived from the China Statistical Yearbook on Environment. The soil erosion area of Huaibei Plain is derived from Anhui Province Annual Communique on Soil and Water conservation monitoring. The land use of Huaibei Plain is obtained from remote sensing data (Fig. 1).

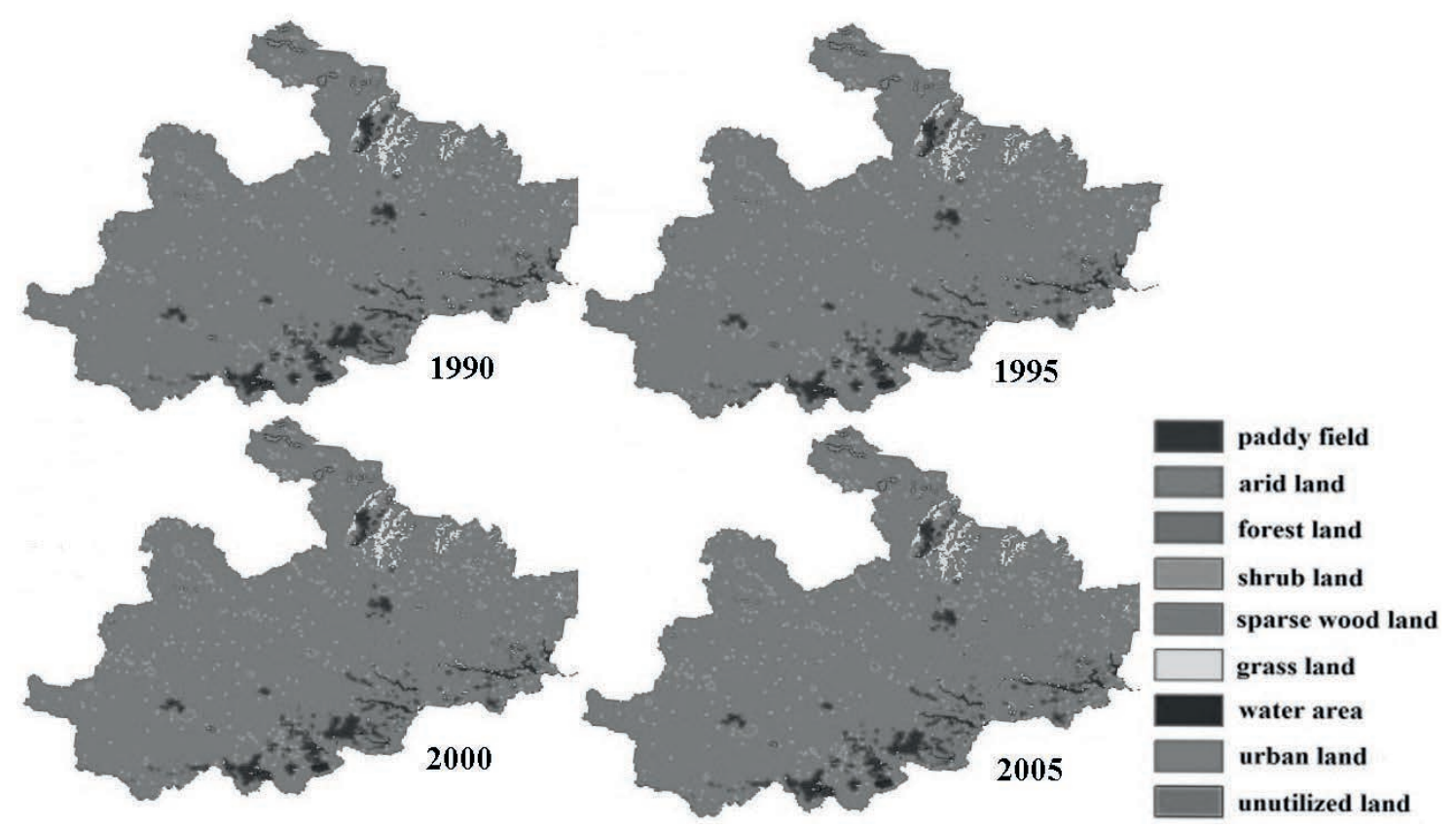

Fig. 1 The distribution of land use/land cover on Huaibei Plain.

\section{Methodology}

Establishment of the evaluation index system The index selection in this paper follows six principles proposed by Wan Bentai (Zhu et al., 2012). NPP has been utilized to instead biological abundance index and vegetation coverage index. NPP is short for net primary productivity, which means that a higher NPP value represents a better eco-environmental system. A better ecoenvironmental system means the biodiversity is greater and vegetation coverage is larger. Thus, NPP is chosen as a new index for the evaluation. This paper selects NPP, water-network density, land retrogression and pollution load as the eco-environmental evaluation indexes. 
The calculation of NPP index To calculate the NPP index in Huaibei Plain, score values of different types of vegetation have been derived (He et al., 2005). We consider the ecosystem of tropical rain forest is the best, and its NPP score value is 1 . The NPP score values of other vegetation are obtained on the basis of the NPP score value of tropical rain forest. The vegetation score values are shown in Table 1.

Total NPP value of Huaibei Plain is calculated based on the area of different vegetation:

$$
N P P_{\text {total }}=\sum\left(S_{i} \times \overline{N P P_{l}}\right)
$$

where $N P P_{\text {total }}(\mathrm{g} /$ year $), \mathrm{S}_{\mathrm{i}}\left(\mathrm{m}^{2}\right)$, and $\overline{N P P_{l}}\left(\mathrm{~g} /\left(\mathrm{m}^{2}\right.\right.$.year) are total NPP value of Huaibei Plain, area of each classified vegetation in Huaibei Plain, corresponding average NPP value, respectively.

Average NPP value of Huaibei Plain is obtained by following equation:

$$
\overline{N P P}=\frac{N P P_{\text {total }}}{S}
$$

where $\overline{N P P}\left(\mathrm{~g} /\left(\mathrm{m}^{2} \cdot\right.\right.$ year $\left.)\right)$ is the average NPP value of Huaibei Plain and $S\left(\mathrm{~m}^{2}\right)$ is the total area of Huaibei Plain.

Finally, we obtain the NPP index using the NPP value of tropical rain forest as reference.

$$
N P P=\frac{\overline{N P P}}{\overline{N P P_{\text {trop }}}}
$$

where $\overline{N P P_{\text {trop }}}\left(\mathrm{g} /\left(\mathrm{m}^{2} \cdot\right.\right.$ year $)$ is the average NPP value of tropical rain forest.

Table 1 Score values of different vegetation.

\begin{tabular}{llll}
\hline Classification & Score value & Classification & Score value \\
\hline Tropical rain forest & 1 & Grassland & 0.26 \\
Deciduous broad leaved forest & 0.57 & Sparse shrubbery & 0.17 \\
Natural mixed forest & 0.47 & Bare soil & 0 \\
Evergreen coniferous forest & 0.54 & Crop & 0.46 \\
Coniferous forest & 0.38 & Water & 0 \\
Ground cover broadleaf forest & 0.72 & Total & 0.38 \\
\hline
\end{tabular}

\section{The calculation of other indexes}

(a) Water-network density index

$$
W D I=\text { River length } / S+\text { Lake area } / S+\text { Water quantity } / S
$$

(b) Land retrogression index. The weight of land retrogression is shown in Table 2.

Table 2 The weight of land retrogression.

\begin{tabular}{llll}
\hline Classification of land retrogression & Mild & Moderate & Severe \\
\hline Weight & 0.05 & 0.25 & 0.7 \\
\hline$L R I=(0.05 \times$ Mild retrogression area $+0.25 \times$ Moderate retrogression area + \\
$0.7 \times$ Severe retrogression area $) / S$
\end{tabular}

(c) Pollution load index. The weight of different pollution index is shown in Table 3.

Table 3 The weight of different pollution index.

\begin{tabular}{llll}
\hline Pollution index & $\mathrm{SO}_{2}$ & $\mathrm{COD}$ & Solid waste \\
\hline Weight & 0.4 & 0.4 & 0.2 \\
\hline \multicolumn{4}{l}{$\begin{array}{l}P L I=0.4 \times \mathrm{SO}_{2} \\
\text { precipitation }\end{array}$}
\end{tabular}


The calculation of eco-environmental quality index The weight of each evaluation index is based on the eco-environmental evaluation method proposed by Wan Bentai. We add the weight of the biological abundance index and vegetation coverage index to give the weight of NPP index. The weights of other indexes are not changed (Table 4).

Table 4 Weight of each evaluation index.

\begin{tabular}{lllll}
\hline Index & NPP & Water-network density & Land retrogression & Pollution load \\
\hline weight & 0.5 & 0.25 & 0.15 & 0.1 \\
\hline
\end{tabular}

The eco-environmental quality index has been denoted as ecological index (EI) in this paper, which ranges between 0 and 100. It can be summarized by the following equation:

$$
E I=0.5 \times N P P+0.25 \times W D I+0.15 \times(1-L R I)+0.1 \times(1-P L I)
$$

where NPP, WDI, LRI, PLI represent separately the net primary productivity, water-network density, land retrogression and pollution load.

To compare the eco-environmental quality of Huaibei Plain, EI was divided into five levels in this paper (Table 5).

Table 5 Classification of eco-environmental quality in Huaibei Plain.

\begin{tabular}{lll}
\hline Classification & EI & Eco-system retrogression degree \\
\hline Best & $\geq 75$ & No retrogression \\
Good & $55-75$ & Slight retrogression \\
Normal & $35-55$ & Normal retrogression \\
Pool & $20-35$ & Strong retrogression \\
Pooler & $<20$ & Complete retrogression \\
\hline
\end{tabular}

\section{RESULTS}

(a) The NPP index falls during the study period, which was mainly caused by the dynamic change of land use (Fig. 2(a)). From 1990 to 2005, the areas of agricultural land decreased by $178 \mathrm{~km}^{2}$. But the areas of construction land increased year by year during the same period, at an increasing rate of $26.84 \%$.

(b) Water-network density index is highly affected by the climate. The annual variation of precipitation is obvious in Huaibei Plain (Fig. 2(b)). Thus, no obvious tendency could be observed. The index is lowest in 2000 due to drought in the spring at that year. The index is highest in 2005 because the precipitation was abundant in that year.

(c) Land retrogression has intensified since 1995 (Fig. 2(c)). The major factor is that the Huaibei Plain has a lime concretion black soil. The structure of this calcareous black soil is fragile and it is easily eroded. At the same time, the vegetation cover has decreased and area of bare soil has increased.

(d) Pollution load index has increased since 1990a for several reasons (Fig. 2(d)). The main reason is the rapid growth of industry in Huaibei Plain. Many factories have been built. However, the pollution from these factories has not been well controlled. Higher levels of industrialization may attract more people to work here. Higher population density is another factor raising the pollution load index.

(e) To sum up, the eco-environmental quality of Huaibei Plain was in a good state during the study period except in 2000 (Fig. 2(e)). The eco-environment quality improved slightly from 1990 to 1995 when the index was 55.38 and 56.87, respectively. In 2000, the ecoenvironmental index was the lowest because the water-network density was the lowest. The eco-environmental quality in 2005 was the highest with 59.01. 


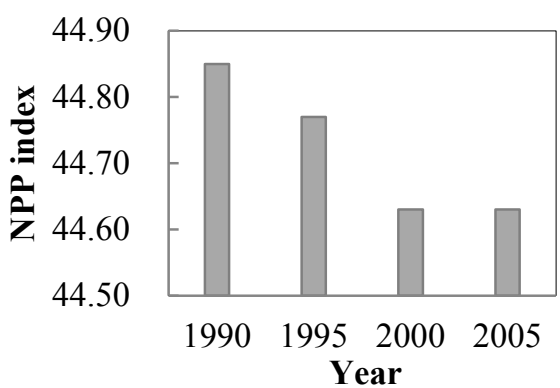

(a) NPP change

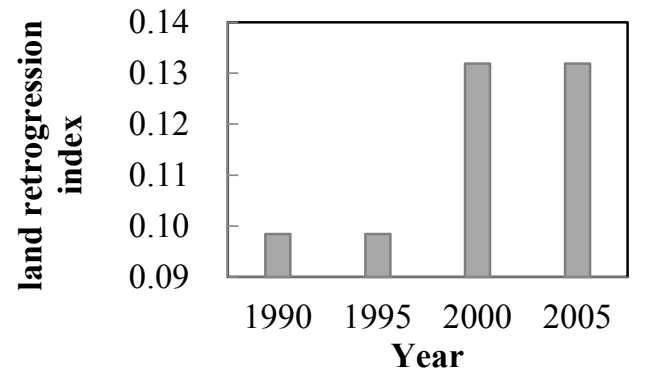

(c) Land retrogression index change

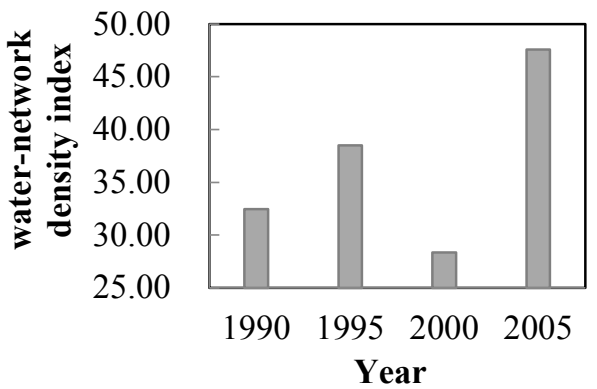

(b) Water-network density index change

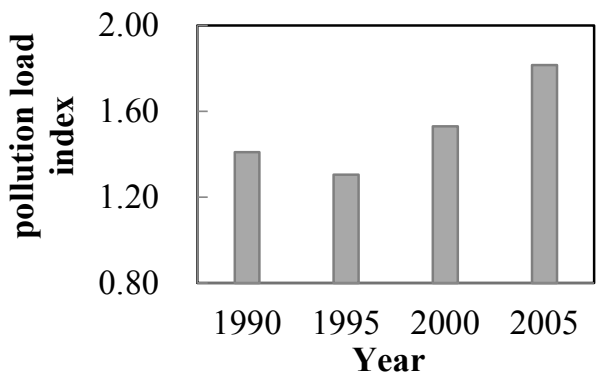

(d) Pollution load index change

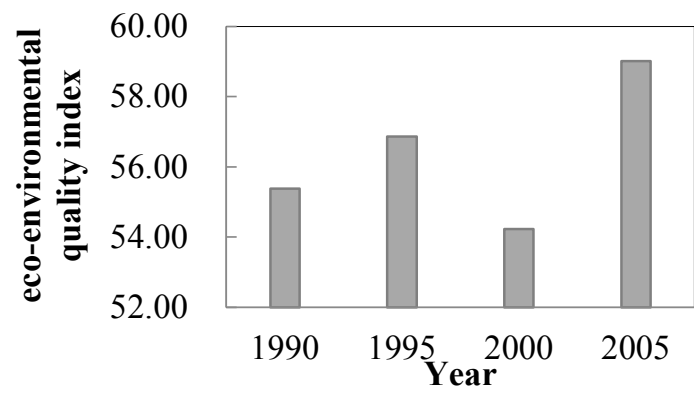

Fig. 2 The change of each index from 1990 to 2005.

The results of the improved eco-environmental quality evaluation method tally with the phenomena we have observed in Huaibei Plain (Fig. 3), which indicates this new method is credible. Also, the NPP index we have used in this paper has taken the spatial variation into consideration, and the result should be more accurate.

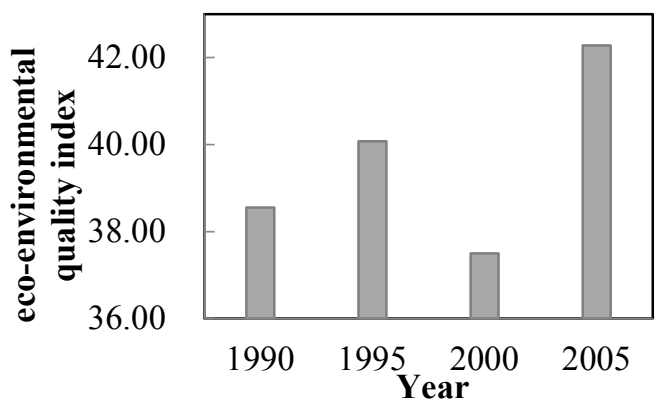

Fig. 3 the result of tradition eco-environment evaluation method

\section{CONCLUSION}

In this paper, NPP has been introduced to replace biological abundance index and vegetation coverage index. A new eco-environmental index is set up to evaluate the dynamic change of the 
eco-environment of Huaibei Plain and gives a satisfactory result. The results show that the ecoenvironmental quality index is greatly affected by the water-network density index. Higher waternetwork density always leads to better eco-environmental quality. This will have a certain reference value for realizing the environment state and planning economic development.

In addition, this paper has some insufficiencies. For instance, because the dynamic change and influence factors of the eco-environment are complex and relative, the factors we select in this paper are not enough; Although we have chosen 1990 to 2005 as our study period, we just analyse the eco-environmental quality in 1990, 1995, 2000, 2005, which means further detailed analysis should be done in future research.

Acknowledgements This research is supported by the National Natural Science Foundation of China (41371049) and the open fund of State Key Laboratory of Desert and Oasis Ecology, Xinjiang Institute of Ecology and Geography, Chinese Academy of Sciences and the National Science Foundation for Outstanding Youth (41125002).

\section{REFERENCES}

He, Y., Dong, W.J. and Qin, D.H. (2005) The terrestrial NPP simulation in China since 6 kaBP. Advances in Climate Change Research 1(2), 69-71.

Li, X.C., Cheng. R.G. and Li, K.Z. (2003) Fuzzy comprehensive valuing and grey forecast for air environmental quality. Systems Engineering-Theory \& Practice 23(4), 124-129.

Li. Z.Y. and Deng, X.M. (1995) Two classes assessment of comprehensive environmental quality based on B-P Neural Network. Research of Environmental Sciences 8(3), 32-35.

Liu, Q.Z. and Wu, Q.H. (2008) Present situation evaluation and research of ecological environment based on GIS. Journal of Guizhou University (Natural Sciences) 25(5), 540-542.

Liu, Y.M. (2013) Deeply implementing the comprehensive planning of Yangtze River Basin, strenuously promoting the construction of water ecological civilization in the basin. Yangtze River 44(10), 1-14.

Meng, Y., et al. (2008) Evaluation of the ecological environment of Shandong Province using MODIS data and GIS platform. Chinese Journal of Eco-Agriculture 16(4), 10201024

Wang, Q.G. and Yu, M.Q. (1997) An urgent need to pay attention to eco-environmental problem. Theory Journal (6), 68-71.

Yu. L. and Yi, W.J. (2002) Application research of Analytic Hierarchy Process (AHP) in urban ecotope quality evaluation. Sichuan Environment 21(4), 38-40.

Zhu, Y.H., et al. (2012) Aquatic Ecosystem Protection and Rehabilitation. Beijing: China Water \& Power Press, $19-26$. 